\title{
A LÍNGUA BRASILEIRA DE SINAIS (LIBRAS) COMO INSTRUMENTO DE EMANCIPAÇÃO SOCIAL E DESENVOLVIMENTO DA IDENTIDADE COLETIVA
}

\author{
Beatriz Ferruzzi Sacchetin ${ }^{1}$, Danielle Aparecida Nascimento Santos ${ }^{2}$ \\ ${ }^{1}$ Graduada em Ciências Sociais pela Universidade Estadual de Campinas - UNICAMP. Especialista em Libras pelo Núcleo de Educação à Distância \\ (NEAD) da Universidade do Oeste Paulista - UNOESTE, Presidente Prudente, SP. E-mail: biafesa@hotmail.com \\ 2 Doutora em Educação pela Universidade Estadual Paulista - UNESP/ Presidente Prudente. Professora do Programa de Pós-Graduação em \\ Educação da Universidade do Oeste Paulista - UNOESTE, Presidente Prudente, SP.
}

\section{RESUMO}

A legislação brasileira educacional ampara pessoas com deficiências em diferentes aspectos, mas tal amparo ainda demonstra fragilidades no que se refere à inclusão desses indivíduos, pois temos uma grande dívida histórica de exclusão. É necessário que as políticas públicas amparem esses sujeitos por meio da valorização dos instrumentos que se mostram eficazes no processo de inclusão. No caso das comunidades surdas brasileiras, a Libras tem grande importância social uma vez que se consolida como oportunidade de comunicação. $O$ objetivo deste trabalho foi analisar a relação entre a consolidação da Libras nas últimas décadas com a construção da identidade coletiva surda. Buscou-se compreender melhor a dinâmica social da inserção dos indivíduos surdos na sociedade por meio da Libras, e fez-se possível compreender que a Libras é um instrumento importante no processo da inserção dos surdos na vida social e uma conquista importante para a afirmação da identidade e da cultura surda.

Palavras-chave: Libras; cultura surda; identidade; autonomia; reconhecimento.

\section{THE BRAZILIAN SIGN LANGUAGE (LIBRAS) AS AN INSTRUMENT OF SOCIAL EMANCIPATION AND DEVELOPMENT OF THE GROUP IDENTITY}

\begin{abstract}
The Brazilian educational law protects disabled people in different ways, but such protection also shows weaknesses in the inclusion of those individuals, because we carry a huge historical debt of social exclusion. It is necessary for public policies to assist those subjects through the valuation of the effective instruments in this process of inclusion. In the case of deaf communities, the "Libras" has great social importance once it established itself as a communication opportunity. The objective of this research was to analyze the relationship between the consolidation of "Libras" in recent decades with the construction of the deaf collective identity. It was pursued to better understand the social dynamics of the integration of deaf people in society through "Libras", thus, it was possible to understand that it is an important tool in the deaf insertion process in society and an important achievement for the affirmation of identity and deaf culture.
\end{abstract}

Keywords: Brazilian Sign Language; deaf culture; identity; autonomy; recognition.

\section{INTRODUÇÃO}

A questão da deficiência é tema de enorme importância para a sociedade de forma geral e apenas recentemente vem sendo discutida na literatura das diferentes áreas de pesquisa, como Educação, Psicologia, Ciências Sociais e História. A pessoa com deficiência desde os tempos mais remotos sofre com o preconceito diário e falta de acesso à vida social, cenário que vagarosamente está sendo alterado. Nas últimas décadas no Brasil, devido a progressos significativos na legislação e a mobilização de sujeitos e grupos para a defesa dos direitos das pessoas com deficiências, diversas situações de grande relevância vêm sendo alteradas.

A importância desse progresso é justamente a aceitação das pessoas com deficiências como cidadãos comuns, com direitos e deveres estabelecidos dentro dos limites possíveis. O reconhecimento do prejuízo histórico 
desses indivíduos devido a preconceitos extremos e a sua aceitação como parte da sociedade é fundamental para que seja possível inseri-los nas situações cotidianas de convivência cultural. A defesa de minorias é um passo muito sério no caminho de sociedades que buscam igualdade material efetiva, ou seja, sociedades capazes de reconhecer as diferenças existentes entre seus integrantes e dar as oportunidades necessárias a cada um.

O papel da Academia, neste sentido, se mostra essencial. Segundo Cromack (2004):

Cumpre esclarecer que existe, ainda, um número muito pequeno de pesquisas realizadas na área de deficiência, em particular na deficiência auditiva. Frente a esse quadro, verifica-se a necessidade de maior dedicação a essa parcela da sociedade, tanto em termos de políticas quanto em termos científicos (CROMACK, 2004, p. 69).

No caso específico dos indivíduos surdos, há um instrumento comunicativo que tomou maior importância nos últimos anos, que é a Língua Brasileira de Sinais (Libras). Há debates fervorosos no tocante aos temas que englobam essa língua, mas é pacífico que o surgimento desse instrumento de comunicação foi de grande importância para toda a comunidade surda. Houve também nos últimos anos a consolidação de uma comunidade surda e a construção de uma "cultura surda", que também foram significativas no tocante ao assunto da surdez.

Este trabalho teve, assim, o objetivo de analisar a relação entre a consolidação da Libras nas últimas décadas com a construção da identidade coletiva surda, dentro da cultura surda. Desse modo, buscou-se demonstrar a importância da existência de políticas que possibilitem o desenvolvimento da Língua materna dos surdos, para que possam construir sua identidade coletiva e conquistarem autonomia e independência social.

\section{METODOLOGIA}

O trabalho foi realizado através de pesquisa relacionada ao conceito de identidade e também à história do paradigma da deficiência e posição social do surdo como minoria cultural e política. A finalidade deste foi compreender os conceitos consolidados na pesquisa no âmbito da emancipação social do surdo, para compreender a dinâmica da relação sócio-política do surdo dentro da sociedade brasileira.

A investigação foi desenvolvida em quatro etapas: 1. Desenvolvimento do tema e dos objetivos; 2. Seleção de material bibliográfico relacionado ao tema; 3 . Leitura e fichamento do material selecionado, para sistematizar as referências obtidas; 4. Análise do material selecionado com base no tema central da pesquisa e nos conhecimentos e reflexões desenvolvidas durante o curso de "Especialização em Libras: Prática e tradução/intérprete", da Universidade do Oeste Paulista, culminando na elaboração do presente artigo.

\section{RESULTADOS}

\subsection{Histórico do status social da pessoa com} deficiência

Segundo Miranda (2003), a deficiência e as pessoas com deficiências sempre enfrentaram dificuldades ao longo da História: desde a falta de inclusão até condenações à morte e torturas na Pré-História e nas Idades Antiga, Média e Moderna. O preconceito e falta de estrutura para inclusão de pessoas com deficiência (nos mais diversos graus) foi resultado da classificação dessas pessoas como "sub-humanos", ou ineficientes. Assim, deve-se considerar que as pessoas com deficiências além de não possuírem quaisquer direitos, sequer eram consideradas humanas.

Assim, com essa exclusão tão radical, não existia qualquer tipo de política pública inclusiva. No caso da surdez, é apenas em 1760 , com a fundação do Instituto nacional de Surdos-mudos de Paris, com Charles-Michel de L'Epeé, que a educação especial começa a ser institucionalizada e dá-se início a uma preocupação maior em educar as pessoas com deficiências. Isso surge porque é percebido que as pessoas que possuem alguma deficiência são tão humanas como quaisquer outras e, por isso, são dotadas de inúmeras capacidades e dificuldades.

Além disso, pode-se dizer que com o avanço das Grandes Navegações e diversas explorações ocorridas na Idade Moderna, era necessária uma quantidade considerável de mãode-obra. Isso fez com que as pessoas com deficiências passassem a ser integradas nesse aspecto laboral (mesmo ainda segregados no âmbito social). 
Surgiram, então, diversos nomes de grande relevância para a História da Educação Especial, que se dedicaram a estudar as mais diversas deficiências a fim de compreendê-las e auxiliar na inclusão dessas pessoas, como Philippe Pinel, Edouard Séguin e Maria Montessori.

No Brasil, o desenvolvimento da Educação Especial diferenciou-se da Europa e dos Estados Unidos e começou a crescer a partir de meados do século XIX. Em 1857 houve a criação do "Instituto dos Surdos-Mudos", no Rio de Janeiro, hoje conhecido como INES (Instituto Nacional de Educação de Surdos). Todavia, o início desse desenvolvimento esteve fortemente marcado por uma educação que visava a "integração", e não uma "inclusão", efetivamente. As pessoas com deficiências tiveram acesso à educação, mas não a uma educação unificada com o restante da população: ainda ficavam em instituições e espaços separados, com reduzida mobilidade social.

No fim do século XX e início do XXI, foi dado um passo em direção à inclusão, principalmente com a promulgação da Constituição Federal de 1988 e leis que regulam aspectos da Educação Especial. As pessoas com deficiências passaram a frequentar aulas juntamente com os demais estudantes, além das horas extras a serem dedicadas em salas de recursos.

A criação da FENEIS (Federação Nacional de Educação e Integração dos Surdos), em 1987, foi um marco histórico muito importante no tocante ao espaço dos surdos no Brasil. A partir dessa data foi possível registrar e ter acesso mais fácil e claro a tudo que se refere à surdez e à cultura surda, tanto no que se refere à profissão de tradução e interpretação como à Libras em si.

Houve nas últimas décadas uma institucionalização, inserção e inclusão dos surdos na sociedade brasileira, bem como dos profissionais atrelados à cultura surda, de modo geral. Segundo Olah e Olah (2010), o momento em que estamos atualmente é especial para a história dos surdos e também dos intérpretes de Libras. Contudo, é importante considerar que os surdos possuem diversas demandas em busca de reconhecimento, pois a situação ainda é de muita discriminação e marginalização desses indivíduos. "Segundo o IBGE o número de surdos no Brasil está na faixa de 5.750 .809 e apenas $3 \%$ desse número concluiu a educação básica" (OLAH; OLAH, 2010, p.1).
Devido às inúmeras demandas para que sejam reconhecidos e tenham seus direitos à igualdade material reconhecidos pelo Estado e pela sociedade como um todo, os surdos passam a fazer diversas reivindicações, reconhecendo a si mesmos como os sujeitos de direito que são. "A constituição da identidade dos surdos passa pela mudança de paradigma da deficiência para o de minoria linguística e cultural" (KAUCHAKJE, 2003, apud CROMACK, 2004, p. 76), com ações coletivas bem estruturadas e repertórios de ação bem definidos.

\subsection{Identidade coletiva e emancipação social}

De acordo com Cromack (2004), os seres humanos são seres sociais e têm a necessidade de se identificar com sua comunidade. Necessitam, ainda, interagir com a sociedade, pois necessitam de uma cultura em que sejam capazes de se inserir e sentir-se pertencentes. Todo ser humano necessita de um conjunto de valores, crenças, ideias, modos e regras para que seja capaz de construir sua própria identidade. Desse modo:

A identidade implica o
processo de consciência
de si próprio, sendo que
esta ocorre por meio de
relações intersubjetivas,
de comunicações
linguísticas e experiências
sociais, tornando-se um
processo ativo (DORON \&
PAROT, 2001, apud
CROMACK, 2004, p. 70).

A identidade é, dessa maneira, um processo construído tanto no plano intrasubjetivo quanto no plano intersubjetivo, e esses planos são dialeticamente conectados e inter-relacionados (Vigotski, 1993, apud CROMACK, 2004, p. 70). Isso significa dizer que é necessário ao ser humano que seja capaz de conectar-se e comunicar-se com o plano intersubjetivo (ambiente exterior, sociedade) para que seja capaz de construir sua própria identidade, no plano intrasubjetivo, pois tal identidade possui diversos aspectos socialmente construídos, e não apenas traços biológicos.

Claramente, com os indivíduos surdos, o processo é o mesmo. Apesar da comunicação se dar de maneira diferente, o processo cognitivo e social do indivíduo surdo é o mesmo do indivíduo ouvinte. Da mesma maneira como o ouvinte, o surdo possui a necessidade de comunicar-se com 
o ambiente externo para que seja capaz de se posicionar nele e construir sua identidade.

[...] É com base nas
significações produzidas
através das relações
sociais, envolvendo esta,
em grande parte, a
relação com os ouvintes,
que o surdo constrói seu
autoconceito.
significação não se dá
somente pelo que
verbaliza ou deixa de
verbalizar, seja isso
concretizado por sons ou
gestos, mas também pelo
lugar social que é
atribuído a essas pessoas
nas relações e pelas
situações de desvantagem
a que são submetidas
numa cultura
hegemonicamente
auditiva (CROMACK, 2004,
p. 71 , grifo nosso)

Para que esse o processo da construção da identidade dos sujeitos baseada na comunicação se concretize, é necessário que haja um sistema simbólico que seja capaz de fazer com que os indivíduos se comuniquem com clareza. A linguagem é, deste modo, um sistema simbólico responsável por criar significados e construir uma história social (GUIMARÃES; CORSINO, p. 7).

\subsection{Libras como fator simbólico de formação da identidade coletiva}

Segundo Barros (2015, p. 131), "a partir do aprendizado da/e por meio da Libras, o sujeito surdo teria condições de constituir sua identidade". Isso significa dizer que a Libras é instrumento comunicativo fundamental para que o surdo seja reconhecido e reconheça a si próprio como sujeito inserido numa cultura, num processo de definição da sua identidade. Um dos aspectos fundamentais para que o surdo seja capaz de se estabelecer na sociedade de maneira independente é estar inserido em uma cultura na qual é capaz de se sentir representado.

A Libras, como qualquer língua dentro de sua respectiva cultura, é fator de extrema importância dentro do processo de construção coletiva. É importante tanto para o autoreconhecimento dos indivíduos surdos num processo que deve ser iniciado desde a infância, quanto para o enfrentamento de preconceitos e desenvolvimento da comunicação junto aos outros membros de sua comunidade.

Autores concordam que a Libras não é o único instrumento emancipatório e formador de identidade para os surdos (BARROS, 2015), mas o espaço que ela é capaz de conquistar para o surdo como ser comunicativo é de extrema importância para que este seja capaz de constituir sua própria subjetividade. A emancipação social do surdo está intrinsecamente ligada às oportunidades que the são dadas de comunicar-se com o ambiente externo e com outros surdos.

A formação de uma cultura surda e de uma comunidade surda são fatores simbólicos de extrema importância que são capazes de representar a maneira como o sujeito sente que é, aumentando sua sensação de representatividade. Há a autoafirmação sobre sua própria identidade e, assim, uma melhora em sua autopercepção, pois percebe que há uma comunidade ao seu redor: não é sozinho e não é o único com determinadas características que o definem.

\subsection{Legislação e reconhecimento profissional do intérprete}

Como ponto final desse terceiro tópico, é bastante relevante que seja colocada em pauta uma questão bastante abordada na literatura que é a importância do crescimento do reconhecimento profissional do tradutor/intérprete nas últimas décadas. Segundo Fleury Avelar (2011), assim como os tradutores de línguas nacionais influenciaram a evolução da linguagem de seus países, os tradutores de Libras influenciam a evolução da língua do surdo brasileiro. Há muita importância dos tradutores na construção de uma consciência coletiva interlinguística entre diferentes grupos, que influencia fortemente na relação intercultural entre esses mesmos grupos.

Historicamente, é a partir do final do século XX que há maior reconhecimento e institucionalização a respeito do trabalho desses profissionais, principalmente com o surgimento da FENEIS, como dito anteriormente. A Lei no 10.436 de 24 de abril de 2002, tem importância cabal na consolidação e na legitimação da Libras no Brasil, mas em 2010 surge ainda uma lei federal que é responsável por regulamentar a profissão de tradutor/intérprete, fazendo com 
que esta fosse mais valorizada e melhor estruturada:

oreconhecimento
profissional do intérprete
por meio da lei no 12.319
de 01 de Setembro de
2010 baseia-se no
trabalho daqueles que
acreditam no direito do
surdo de ter acesso ao que
o ouvinte tem e, além
disso, baseia-se no fato de
que o intérprete não é um
indivíduo que gesticula ao
vento para ajudar o
"pobre" do surdo, e sim
um tradutor que possui
habilidades re
competências (OLAH;
OLAH, 2010, p. 5).

Importante ainda dizer que para que o tradutor/intérprete seja capaz de exercer seu trabalho, é necessário que tenha capacidade tradutória, e não apenas ser bilíngue. Ou seja, é uma profissão muito séria para a qual se deve ter uma responsabilidade e uma formação muito sólidas, pois muitas vezes implica em acesso a situações muito íntimas e particulares para os surdos.

Isso posto, pode-se dizer que com um maior reconhecimento da profissão, há também uma melhor estruturação da própria Libras tanto entre os surdos quanto entre os ouvintes. Como consequência desse processo, os surdos têm uma oportunidade ampliada de acesso à comunicação, o que implica diretamente numa melhor autoafirmação de sua identidade.

\section{DISCUSSÃO}

Uma manifestação a respeito de uma minoria, qualquer que seja, exige sempre a exposição da relevância da igualdade material entre indivíduos de uma mesma sociedade. Não se trata, assim, de discorrer a respeito da igualdade em si, em que todos são considerados iguais idealmente. Trata-se de desenvolver a ideia da igualdade em que todos são desiguais e assim devem ser tratados.

A importância da busca por essa igualdade efetiva se dá por diversos motivos, entre eles a garantia de direitos (expressamente previstos na própria Constituição Federal Brasileira), a inclusão de indivíduos que são marginalizados pela dinâmica social e a reflexão profunda que pode ser produzida a respeito desse processo. No caso dos surdos, é necessário que haja uma estrutura de acessibilidade muito bem consolidada para que esses indivíduos sejam capazes de se sentir pertencentes e verdadeiramente incluídos na sociedade. Esse desenvolvimento se mostra de grande importância não apenas para os surdos, mas também para os ouvintes, ao passo que ensina valores de convivência extremamente importantes, que podem ser deslocados para diversos outros âmbitos de interação.

Nesse processo da busca pela igualdade através da inclusão, há não só o aspecto objetivo, relativo à questão de oportunidades e contato social, mas também o aspecto subjetivo, relativo à construção da identidade dos indivíduos baseada em suas interações sociais e autopercepção. Deste modo, é essencial que os indivíduos compartilhem suas experiências para que se compreendam como parte da sociedade e tenham a sensação de pertencimento em algum grupo social. Os indivíduos surdos, devido a uma particularidade muito grande exatamente nessa dinâmica de compartilhamento de experiências, tornam-se um grupo particular no tocante à construção de sua identidade coletiva.

"Para que a construção da identidade surda aconteça é essencial o encontro surdosurdo" (PAULA, 2009, p. 413). Isso significa que a construção de uma "cultura surda" é essencial para que o surdo construa a ideia de quem é e quais são suas necessidades no caminho para o convívio social. A interação recíproca entre surdos é de grande importância para que seja possível, inclusive, que demandas sejam propostas no tocante à luta por direitos de inclusão.

\section{CONCLUSÃO}

A partir do momento em que os surdos são capazes de entender-se como comunidade e construir uma forte identidade coletiva, é possível que haja uma sensação de empoderamento muito valiosa. É ainda necessário que os ouvintes sejam conscientizados a respeito da importância da inclusão dos surdos e da representatividade que devem ter em todas as esferas da vida social, mas é a partir do momento em que os próprios surdos percebem isso que é possível a luta nesse sentido. É no contato com a cultura surda, num sentido mais amplo, que o indivíduo surdo é capaz de se 
enxergar como surdo e compreender os próprios problemas que enfrenta em seu dia-a-dia.

A Libras, que através de iniciativas legislativas e processos sociais foi mais bem consolidada nas últimas décadas no Brasil, é um instrumento de grande importância para o desenvolvimento desse processo de construção de identidade coletiva e empoderamento dos indivíduos surdos. Não é o único, mas é justamente o instrumento que torna clara a comunicação dos indivíduos surdos com o ambiente externo, o plano intersubjetivo. Isso significa dizer que quanto mais bem estruturada encontra-se essa língua no Brasil (e isso inclui o ensino de Libras para indivíduos ouvintes), mais fácil se torna a assimilação do processo social de inclusão para os surdos.

Por fim, aspecto que se revelou importante nessa estruturação da Libras no país foi a valorização da profissão de tradução/interpretação de Libras e a especialização dos indivíduos que se dedicam a essa profissão. É com uma institucionalização e aperfeiçoamento do sistema de comunicação dos surdos que estes serão capazes de ser efetivamente incluídos, e que os ouvintes serão capazes de perceber tamanha importância do reconhecimento dos surdos na construção de valores de convivência nos mais diversos âmbitos de interação social.

\section{REFERÊNCIAS}

BARROS, E. M. Ações coletivas, identidade e mobilizações políticas: movimento social surdo e a luta por reconhecimento. 2015. $149 \mathrm{f}$. Tese (Mestrado em Sociologia) - Instituto de Filosofia e Ciências Humanas, Universidade Estadual de Campinas, Campinas, 2015.

CROMACK, E. M. P. C. Identidade, cultura surda e produção de subjetividades e educação: atravessamentos e implicações sociais. Psicol. Cienc. Prof., Brasília , v. 24, n. 4, p. 68-77, dez. 2004.

FLEURY AVELAR, T. O papel da tradução no desenvolvimento da Língua de Sinais Brasileira (Libras): um breve histórico. Trama, Marechal Cândido Rondon, v. 7, n. 14, p. 1-10.

MIRANDA, A. A. B. História, deficiência e educação especial. Histedbr, Campinas, n. 15, p. 1-7, set. 2003.
OLAH, L. V. A. S. ; OLAH, N. C. S.. O intérprete de Libras e a inclusão social do surdo. Revista Pandora Brasil, São Paulo, n. 24, p. 1-6, nov. 2010.

PAULA, L. S. B. Cultura escolar, cultura surda e construção de identidades na escola. Revista Brasileira de Educação Especial, Marília, v. 15, n. 3, p. 407-416, dez. 2009.

Recebido para publicação em: 08/08/2017

Revisado em: 25/09/2017

Aceito em: 27/09/2017 